\title{
Loss of Wnt Secretion by Macrophages Promotes Hepatobiliary Injury after Administration of 3,5-Diethoxycarbonyl-1, 4-Dihydrocollidine Diet
}

An Jiang, ${ }^{\star \dagger}$ Hirohisa Okabe, ${ }^{\dagger \dagger \S}$ Branimir Popovic, ${ }^{\dagger \ddagger}$ Morgan E. Preziosi, ${ }^{\dagger \dagger}$ Tirthadipa Pradhan-Sundd, ${ }^{\dagger \ddagger}$ Minakshi Poddar, ${ }^{\dagger \ddagger}$ Sucha Singh, ${ }^{\dagger \dagger}$ Aaron Bell, ${ }^{\dagger \dagger}$ Steven G. England, ${ }^{\top}$ Shanmugam Nagarajan, ${ }^{\dagger \ddagger \|}$ and Satdarshan P. Monga ${ }^{\dagger \ddagger}$

From the National-Local Joint Engineering Research Center of Biodiagnostics and Biotherapy, * Department of General Surgery, Second Affiliated Hospital, Xi'an Jiaotong University, Xi'an, People's Republic of China; the Department of Pathology, ${ }^{\dagger}$ University of Pittsburgh School of Medicine, Pittsburgh, Pennsylvania; the Pittsburgh Liver Research Center, ${ }^{\ddagger}$ University of Pittsburgh and University of Pittsburgh Medical Center, Pittsburgh, Pennsylvania; the Graduate School of Life Sciences, ${ }^{\S}$ Kumamoto University, Chuo-Ku Kumamoto, Japan; Division of Future Therapeutics and Technologies, ${ }^{\circledR}$ Abbvie, North Chicago, Illinois; and the Department of Pathology and Laboratory Medicine," University of North Carolina at Chapel Hill, Chapel Hill, North Carolina

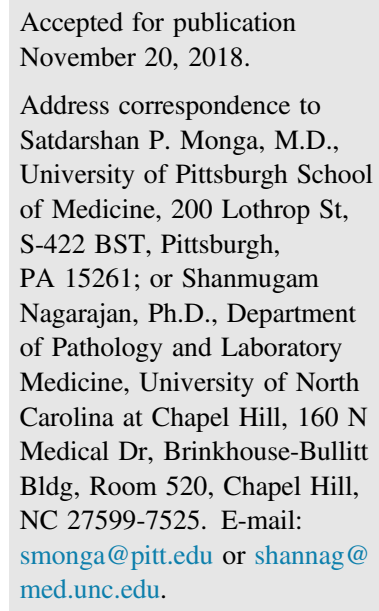

\begin{abstract}
Exposure of mice to a diet containing 3,5-diethoxycarbonyl-1, 4-dihydrocollidine (DDC) induces porphyrin accumulation, cholestasis, immune response, and hepatobiliary damage mimicking hepatic porphyria and sclerosing cholangitis. Although $\beta$-catenin signaling promotes hepatocyte proliferation, and macrophages are a source of Wnts, the role of macrophage-derived Wnts in modulating hepatobiliary injury/repair remains unresolved. We investigated the effect of macrophage-specific deletion of Wntless, a cargo protein critical for cellular Wnt secretion, by feeding macrophage-Wntless-knockout (Mac-K0) and wild-type littermates a DDC diet for 14 days. DDC exposure induced Wnt11 up-regulation in macrophages. Mac-KO mice on DDC showed increased serum alkaline phosphatase, aspartate aminotransferase, direct bilirubin, and histologic evidence of more cell death, inflammation, and ductular reaction. There was impaired hepatocyte proliferation evidenced by Ki- 67 immunostaining, which was associated with decreased hepatocyte $\beta$-catenin activation and cyclin-D1 in Mac-KO. Mac-KO also showed increased CD45, F4/80, and neutrophil infiltration after DDC diet, along with increased expression of several proinflammatory cytokines and chemokines. Gene expression analyses of bone marrow-derived macrophages from Mac- $\mathrm{KO}$ mice and $\mathrm{F} 4 / 80^{+}$macrophages isolated from DDC-fed MacKO livers showed proinflammatory M1 polarization. In conclusion, this study shows that a lack of macrophage Wnt secretion leads to more DDC-induced hepatic injury due to impaired hepatocyte proliferation and increased M1 macrophages, which promotes immune-mediated cell injury. (Am J Pathol 2019, 189: 590-603; https://doi.org/10.1016/j.ajpath.2018.11.010)
\end{abstract}

Chronic liver diseases share a common pathologic mechanism, liver-injury stimulated fibrosis, which, if progressive, can lead to cirrhosis, liver failure, and cancer. ${ }^{1}$ The inflammatory response to chronic liver injury, mediated by parenchymal and nonparenchymal cells, plays critical roles in fibrosis. Fibrosis is an adaptive response to liver injury that facilitates tissue repair. Clinical observations and experimental models suggest that liver fibrosis is a dynamic, bidirectional process with the capacity for recovery even at advanced stages. ${ }^{2}$ A better understanding of the mechanisms of fibrosis, repair, and the role of inflammatory cells and mediators is crucial to developing new therapeutic approaches.

\footnotetext{
Supported in part by NIH grants 1R01DK62277, 1R01DK100287, R01CA204586, and R01HL130126 (S.N.); Abbvie Pharmaceuticals research grant I\# 0050815 (S.P.M.); an Endowed Chair for Experimental Pathology (S.P.M.); and China Scholarship Council grant 201406285033 (A.J.).

Disclosures: S.P.M. is a consultant for Abbvie and Dicerna and has a research grant from Abbvie. S.G.E. is an employee of Abbvie.
} 
In an acute liver injury, hepatocytes contribute by regenerating injured parenchymal cells. In a severe or chronic injury, hepatic progenitor cells, which may arise from cholangiocytes, contribute to hepatocyte regeneration. Activation of hepatic progenitor cells is associated with the development of a ductular reaction and fibrosis in chronic liver diseases. ${ }^{3,4}$ Notably, hepatic progenitor cells are believed to coexist in a milieu with leukocytes, including macrophages. It is conceivable that cells such as macrophages may contribute to hepatic progenitor cell activation and differentiation. Macrophages play critical and spatiotemporal roles in liver regeneration, fibrosis development, and resolution of inflammation. ${ }^{5-7}$ Macrophages in bone marrow fraction have been shown to induce ductular reaction due to tumor necrosis factor-like weak inducer of apoptosis. ${ }^{8}$ Another study has shown resident macrophages to be critical in migration of progenitors. ${ }^{9}$ Macrophage ablation at time of injury led to decreased fibrosis, whereas their ablation during resolution of fibrosis led to persistent fibrosis, suggesting temporal and potentially opposing functions of these cells. ${ }^{5}$ Last, macrophages, by virtue of being the source of vascular endothelial growth factor, were shown to play a role in regulating endothelial cell function and in turn in extracellular matrix turnover. ${ }^{10}$ The macrophages, as a source of Wnts, in the context of hepatobiliary injury are currently poorly understood.

The Wnt family contains 19 secreted glycoproteins that can stimulate target cells to regulate cell proliferation, differentiation, and migration via $\beta$-catenin and $\beta$-catenin-independent pathways. ${ }^{11}$ Wnt signaling drives hepatocellular differentiation during development, ${ }^{1,12}$ and a similar function for Wnts during chronic liver injury has been suggested. ${ }^{13}$ Multiple studies in rodent models of chronic liver disease have also suggested a role for $\beta$-catenin signaling in chronic liver injury, including driving hepatic cellular proliferation and differentiation. ${ }^{14-16}$ A loss-offunction mutation in the LRP6 gene, encoding a Wnt coreceptor, was recently associated with human nonalcoholic fatty liver disease. ${ }^{17}$ Earlier studies have also shown that macrophage- but not epithelial-derived Wnts contribute to liver regeneration after partial hepatectomy. ${ }^{12}$ When $\beta$-catenin conditional knockout mice, that lacked $\beta$-catenin in hepatocytes and cholangiocytes, were fed a cholestatic hepatic injury-causing diet containing $0.1 \% \quad 3,5$ diethoxycarbonyl-1,4-dihydrocollidine (DDC) for a shortterm, less progenitor cell response was found. However, long-term DDC feeding led to increased inflammatory cell infiltration and fibrosis. ${ }^{14}$ It was also recently reported that DDC diet-induced injury increased expression of Wnt7a, Wnt7b, and Wnt10a, which led to hepatobiliary repair observed as increased expression of epithelial cell adhesion molecule and transcription factor SOX-9 (Sox9). ${ }^{18}$ Recently, Wnt secretion from hepatic stellate cells was shown to be dispensable in causing hepatic fibrosis in two different injury models. ${ }^{19}$ The role of macrophage-derived Wnt proteins in hepatobiliary repair during cholestatic injury remains unknown.
In the current study, we investigated the contribution of macrophage-derived Wnts to the overall inflammatory milieu, injury, fibrosis, and repair, during DDC diet-induced liver disease by using myeloid-targeted deletion of Wntless $(W l s)$. Wls encodes the chaperone Wls, which is specifically required for all Wnt secretion from a cell. ${ }^{20}$ Thus, elimination of Wls from myeloid cells prevents secretion of all Wnts from these cells, including monocytes and macrophages. However, although this model falls short on allowing study of a specific Wnt ligand, it allows for elucidating the role of macrophages as source of Wnts during DDC-induced hepatobiliary injury and repair. Interestingly, macrophage-Wntless-knockout (Mac-KO) mice after DDC diet had notably more inflammation compared with control. Some inflammatory cells (eg, CD45- and neutrophil elastase-positive cells) were more abundant in Mac-KO mice after DDC treatment, which may lead to more injury and ductular reaction in the Mac-KO mice. Overall, these studies suggest that a lack of Wnt secretion from macrophages under inflammatory conditions may exacerbate injury by perpetuating inflammation and hindering repair.

\section{Materials and Methods}

Mice

Macrophage-specific Wls KO mice (Mac-KO: Wls ${ }^{\text {loxp/loxp }}$, $L y z 2-\mathrm{Cr}^{+/-}$) were generated by crossing $\mathrm{Wls}^{\text {floxflox }}$ mice with $\mathrm{LyzM}_{\mathrm{Cr}} \mathrm{Cr}^{+-}$mice. Littermates with floxed target genes but without Cre (Wls ${ }^{\text {floxfflox }} ; \mathrm{Lyz}_{2}-\mathrm{Cre}^{-/-}$and Wls $\left.{ }^{\text {flox/wt }} ; \mathrm{Lyz} 2-\mathrm{Cre}^{-/-}\right)$were used as controls. Genomic DNA was extracted using QIAamp DNA Micro Kit (Qiagen, Hilden, Germany) from F4/80 $0^{+}$macrophages. For PCR analysis on deleted Wls allele, the following primer sets (forward and reverse, respectively) were used: Wls-P1, $5^{\prime}$-CTTCCCTGCTTCTTTAAGCGTC-3' (forward); and Wls-P4, $5^{\prime}$-CTCAGAACTCCCTTCTTGAAGC-3' (reverse). ${ }^{20}$ The amplification protocol comprised an initial incubation at $95^{\circ} \mathrm{C}$ for 4 minutes and 30 cycles of $94^{\circ} \mathrm{C}$ for 30 seconds, $62^{\circ} \mathrm{C}$ for 30 seconds, and $72^{\circ} \mathrm{C}$ for 40 seconds, and a final extension of $72^{\circ} \mathrm{C}$ for 7 minutes. The use of these primers produces the band of $410 \mathrm{bp}$ for the Wls allele. All experiments were performed under strict guidelines of the NIH's Guide for the Care and Use of Laboratory Animals ${ }^{21}$ and the Institutional Animal Use and Care Committee at the University of Pittsburgh (Pittsburgh, PA).

\section{DDC-Diet-Induced Liver Injury}

Mac-KO and corresponding control mice (male, age 6 weeks) were fed $0.1 \%$ DDC diet for 2 weeks, as described in our earlier publication. ${ }^{14,18}$ Mice were sacrificed after 2 weeks of DDC diet. Blood and livers were collected for subsequent analyses. Liver was excised, and a portion was fixed in $10 \%$ neutral-buffered formalin and processed for paraffin embedding. A portion of liver was frozen in 
Tissue-Tek OCT compound (Sakura Fintek, Torrance, CA) for frozen sections. The remaining liver was quickly frozen in liquid nitrogen and stored at $-80^{\circ} \mathrm{C}$.

\section{Serum Biochemistry}

Blood samples were collected from the orbital sinus at the time of sacrifice. Serum biochemical measurements for total bilirubin, direct bilirubin, alkaline phosphatase, aspartate aminotransferase, and alanine aminotransferase were performed by the Biospecimen Biorepository and Processing Core of the Pittsburgh Liver Research Center at the University of Pittsburgh and University of Pittsburgh Medical Center.

\section{Immunohistochemistry and Immunofluorescence}

Tissues were fixed in $10 \%$ buffered formalin and embedded in paraffin, and sections ( $4 \mu \mathrm{m}$ thick) were used for hematoxylin and eosin staining, immunohistochemistry (IHC), or immunofluorescence. Briefly, for IHC, deparaffinized sections were incubated in $3 \% \mathrm{H}_{2} \mathrm{O}_{2}$ in $1 \times$ phosphate-buffered saline for 10 minutes to quench the endogenous peroxidase. Slides were pressure cooked in antigen retrieval buffer
(Dako, Glostrup, Denmark) for 20 minutes. Subsequently, slides were washed and incubated with super block buffer (Thermo Fisher Scientific, Pittsburgh, PA) to suppress nonspecific binding, then incubated with primary antibodies in phosphate-buffered saline with $1 \%$ bovine serum albumin overnight at $4{ }^{\circ} \mathrm{C}$. After washes, the sections were incubated in the appropriate biotin-conjugated secondary antibody (Chemicon, Temecula, CA), for 30 minutes at room temperature. Signal was detected using the Vectastain ABC Elite kit (Vector Laboratories, Inc., Burlingame, CA) and developed using diaminobenzidine (Vector Laboratories, Inc.). For immunofluorescence, sections were incubated in the dark with fluorescein isothiocyanate-conjugated goat anti-rabbit and tetramethylrhodamine-conjugated goat antirat secondary antibody (1:500) in 1\% bovine serum albumin in phosphate-buffered saline for 1 hour. Then, after another wash with phosphate-buffered saline, sections were counterstained with $1 \mathrm{mg} / 100 \mathrm{~mL}$ DAPI (B2883; MilliporeSigma, Burlington, MA) and mounted using mounting medium containing DAPI. Samples were imaged on a Nikon Eclipse Ti epifluorescence microscope (Nikon Instruments Inc., Melville, NY). Apoptotic nuclei were detected by the terminal deoxynucleotidyl transferasemediated dUTP nick-end labeling staining using the

Table 1 Primers and PCR Assays Used

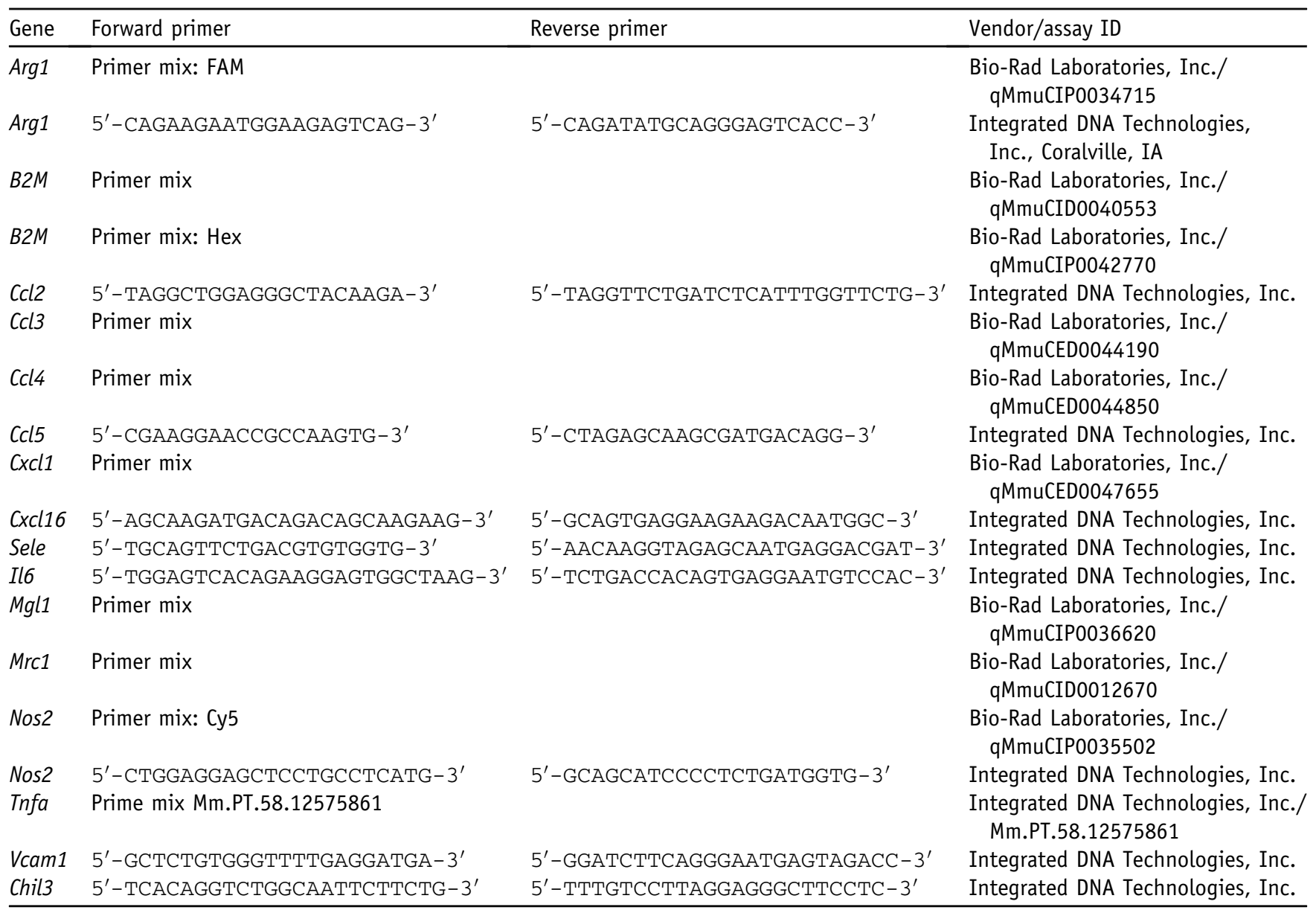


A

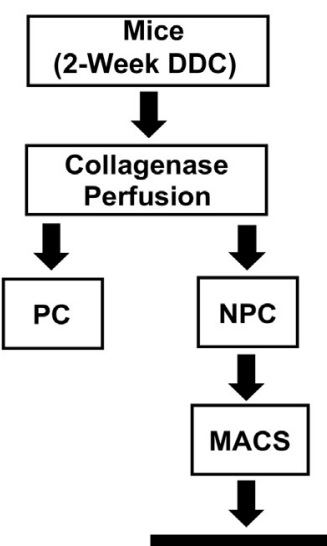

F4/80+ Cells
B
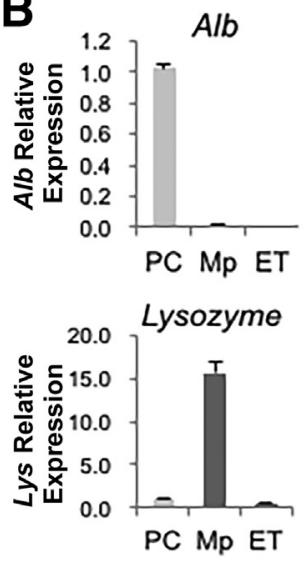

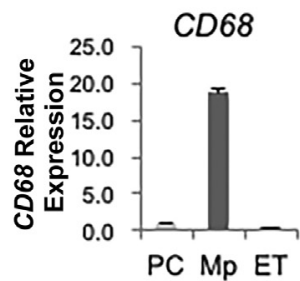

Tie2

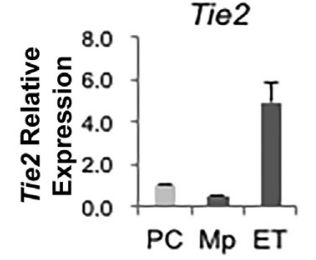

C F4/80+ Cells (WT)

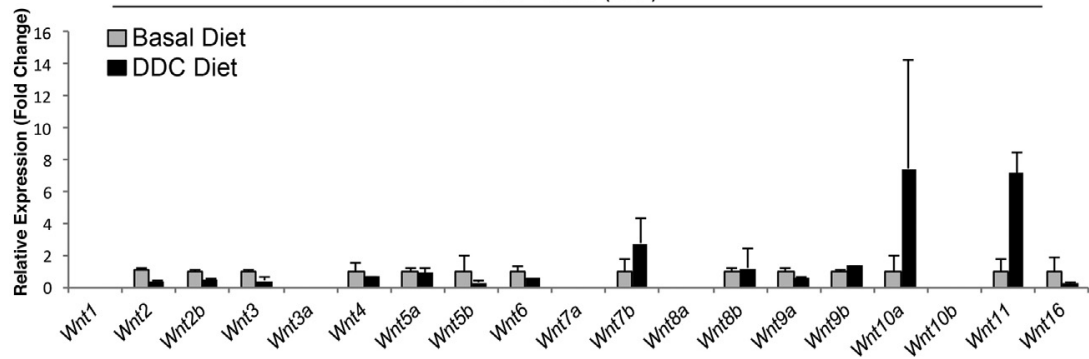

D

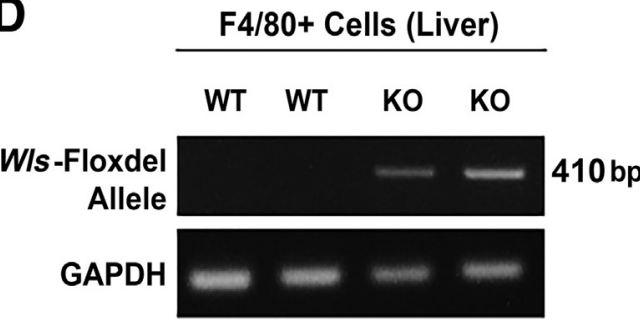

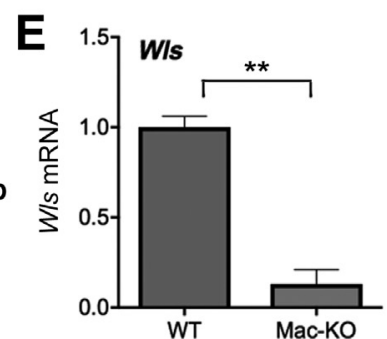

Figure 1 Macrophage isolation to characterize DDC-diet-induced changes in Wnt expression and generation of Mac-KO mice. A: Schematic of isolation of various cells after collagenase perfusion, including parenchymal cells (PCs) and nonparenchymal cells (NPCs). NPC fraction was used to isolate macrophages (F4/80) using magnetic-activated cell sorting. B: Purity of cell fractions was verified by both the presence of positive markers in various cell types and simultaneous absence of negative cell-specific markers by real-time quantitative RT-PCR (RT-qPCR). Alb (hepatocytes), CD68, lysozyme [macrophages (Mp)], and Tie2 [endothelial cells (ET)] are seen. Epithelial cell adhesion molecule-positive and CD45-positive cells were separated from nonparenchymal cells after liver perfusion. Two mice fed DDC diet for 2 weeks were used for cell isolation, and isolated cell fractions were pooled for analysis. C: $\mathrm{F} 4 / 80^{+}$macrophages were isolated and pooled from livers of two mice on normal and two mice on DDC diet for 2 weeks and subjected to RT-qPCR analysis. A notable increase in Wnt11 mRNA expression is observed along with elevation of Wnt7b and Wnt10a in DDC-fed group versus mice on basal diet. Data presented as relative expression, fold change. D: Confirmation of Wls genetic deletion in Mac-KO mice using PCR on DNA from isolated macrophages from two mice from each genotype. Deletion of the floxed Wls exon results in 410-bp band. E: RT-PCR expression analysis of Wls mRNA in isolated macrophages from three WT and three Mac-KO mice shows substantial reduction in Wls expression in Mac-KO mice. Data are expressed as relative expression, fold change. ${ }^{*} P<0.01$. GAPDH, glyceraldehyde-3phosphate dehydrogenase.
ApopTag Peroxidase kit (Intergen Company, Purchase, NY).

Primary antibodies used in the study include anti-glutamine synthase (GS; 1:50 dilution, SC9067, Santa Cruz Biotechnology, Dallas, TX), anti-cyclin D1 (1:50, 9041-po, Lab Vision \& Neomarkers, Fremont, CA), anti-CD45 (1:100, SC53665, Santa Cruz Biotechnology), anti-neutrophil elastase (1:1500, AB68672, Abcam Biotechnology, Cambridge, MA), anti-F4/80 (1:100, MCA497GA, Bio-Rad Laboratories, Inc., Hercules, CA), anti- $\alpha$-smooth muscle actin (1:100, M0851, Dako), anti-Sox9 (1:100; AB5535, MilliporeSigma), and anti-cytokeratin 19 (CK19; 1:10; TRoma III; DSHB Biotechnology, Iowa City, IA).

\section{Western Blot Analysis}

Liver lysates were prepared by homogenizing liver tissues in radioimmunoprecipitation assay buffer with protease and phosphatase inhibitors, and 30 to $40 \mu \mathrm{g}$ of protein was subjected to SDS-PAGE and Western blot analyses. ${ }^{18,22}$ The primary antibodies used in the study include anti- $\beta$ catenin (BD610154; BD Biosciences, San Jose, CA), anti-active $\beta$-catenin that recognizes $\beta$-catenin hypophosphorylated at serine-37 and threonine-41 (1:100; Upstate Biotechnology, Lake Placid, NY), anti-GS (1:50 dilution, SC9067, Santa Cruz Biotechnology), and anticyclin D1 (1:50, 9041-po, Lab Vision \& Neomarkers).

\section{Generation of BMDMs}

Bone marrow cells were isolated from femur and tibias of wild-type and Mac-KO mice $(n=3)$ fed chow diet. Bone marrow cells $\left(5 \times 10^{6}\right.$ /plate $)$ were plated in $100-\mathrm{mm}$ petri dishes in Dulbecco's modified Eagle's medium supplemented with $10 \%(\mathrm{v} / \mathrm{v})$ fetal bovine serum, $2 \mathrm{mmol} / \mathrm{L}$ L-glutamine, $100 \mathrm{U} / \mathrm{mL}$ penicillin, $100 \mu \mathrm{g} / \mathrm{mL}$ streptomycin, $1 \times$ minimal essential medium nonessential amino acids, 1 $\mathrm{mmol} / \mathrm{L}$ sodium pyruvate, and $20 \%$ L929 supernatant 

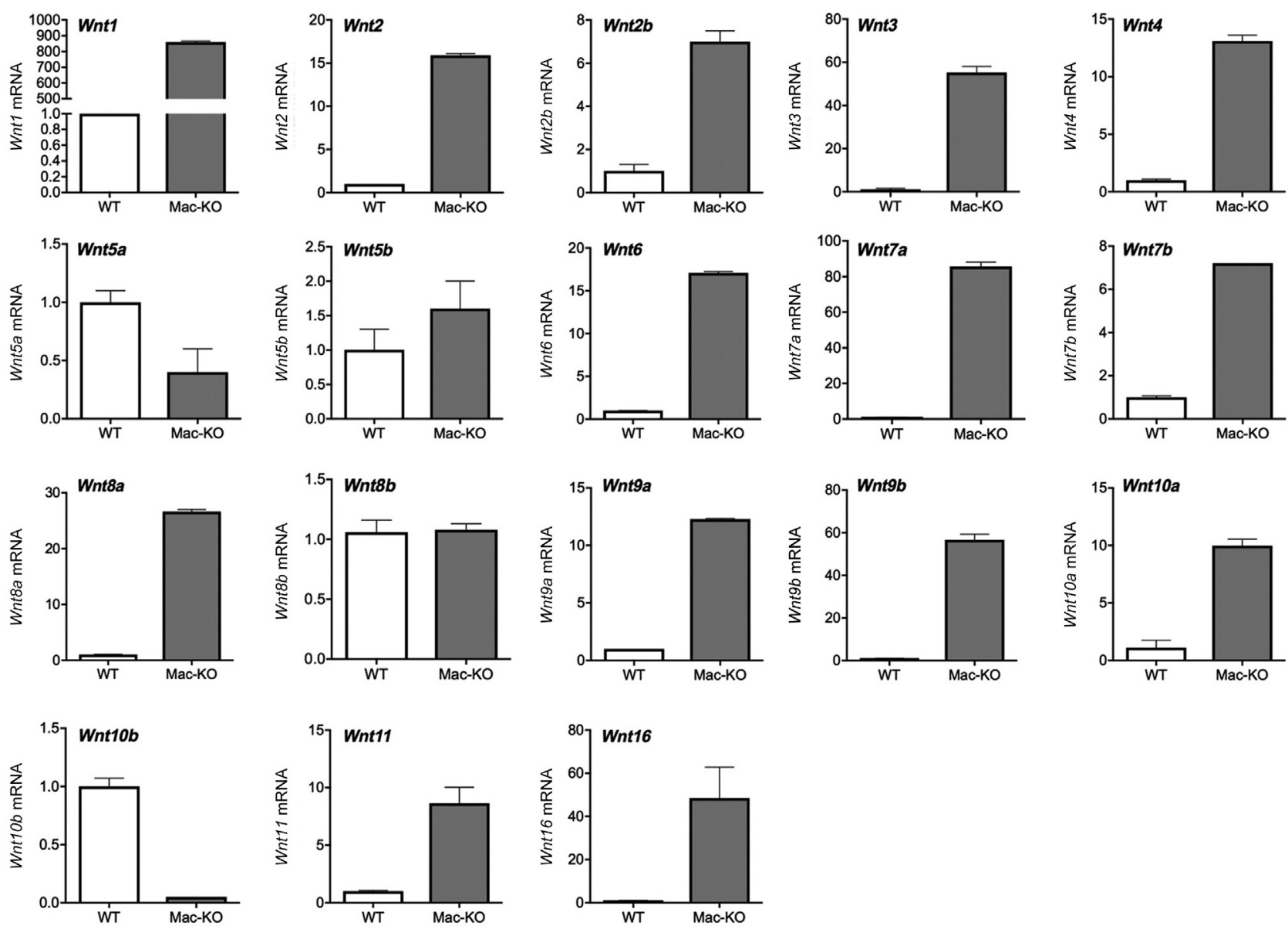

Figure 2 Changes in Wht gene expression in macrophages with Wls deletion. Real-time quantitative RT-PCR for a panel of Wnt ligands on bone marrow-derived macrophages (BMDMs) from WT and Mac-K0 mice shows expression of all 16 Wnt genes. However, several Wnt genes (Wnt1, Wnt2, Wnt2b, Wnt3, Wnt4, Wnt5b, Wnt6, Wnt7a, Wnt7b, Wnt8a, Wnt9a, Wnt9b, Wnt10a, Wnt11, and Wnt16) are up-regulated manyfold in the baseline Mac-K0 BMDMs compared with BMDMs from WT mice. Wnt5a and Wnt10b are notably down-regulated, whereas there is no change in the expression of Wnt8b. The expression of each Wnt gene is normalized to glyceraldehyde-3-phosphate dehydrogenase and expressed as fold-change in Mac-KO over WT mice. Three Mac-KO or WT mice were used for isolating and differentiating BMDMs.

(source of macrophage colony-stimulating factor) to generate bone marrow-derived macrophages (BMDMs). Additional medium was added after 3 days, and cells were harvested at day 7. BMDM cells were incubated for 6 hours with $50 \mathrm{ng} / \mathrm{mL}$ mouse interferon- $\gamma$ plus $10 \mathrm{ng} / \mathrm{mL}$ lipopolysaccharide or $20 \mathrm{ng} / \mathrm{mL}$ mouse IL-4 to induce M1 and M2 macrophages, respectively. BMDMs incubated with medium alone were treated as M0 macrophages.

\section{Cell Separation, RNA Isolation, and Real-Time Quantitative RT-PCR}

Total RNA was isolated using either Trizol (Invitrogen, Waltham, MA) or RNeasy Mini Kit (Qiagen). ${ }^{18,22}$ After DNase treatment, cDNA was prepared using $(0.3$ to $1 \mu \mathrm{g})$ total RNA and SSOAdvanced iScript kit (Bio-Rad Laboratories, Inc.), according to the manufacturer's instruction. Real-time quantitative RT-PCR was performed on a BioRad CFX96 using SSO-advanced SYBR Green PCR Master Mix (Bio-Rad Laboratories, Inc.). To determine the macrophage-specific elimination of Wls, positive selection of $\mathrm{F} 4 / 80^{+}$cells from nonparenchymal cells was performed using the QuadroMACS column separation kit (Miltenyi Biotech, Cambridge, MA), as described earlier. ${ }^{18}$ The purity of $\mathrm{F} 4 / 80^{+}$cells was verified by real-time quantitative RTPCR using primers for absence of negative markers albumin (hepatocyte specific) and tyrosine kinase with Ig and EGF homology domains-2 (Tie2; specific for endothelial cells) and for presence of Cd68 (macrophage). In some experiments, macrophages were isolated from DDC-fed mice. Briefly, $\mathrm{F} 4 / 80^{+}$macrophages were fluorescenceactivated cell sorted (FACSAria; BD Biosciences) after staining nonparenchymal cells with F4/80phosphatidylethanolamine (Biolegend, San Diego, CA). Purity of the $\mathrm{F} 4 / 80^{+}$macrophages isolated from liver tissue was $>98 \%$, and cells were lysed in Trizol and RNA prepared using DirectZol (Zymo Research, Irvine, CA) method. Expression of Nos2 and Argl was determined by TaqMan probe using gene-specific primers and probes (Bio-Rad Laboratories, Inc.) in Bio-Rad CFX thermocycler. Two-step 


\section{A WT: Evi loxp $+/+$ Lyz Cre $-/-$ \\ Mac-KO: Evi loxp +/+ Lyz Cre +/-

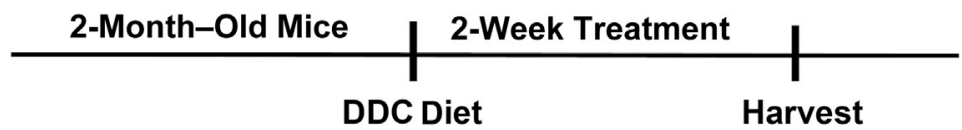

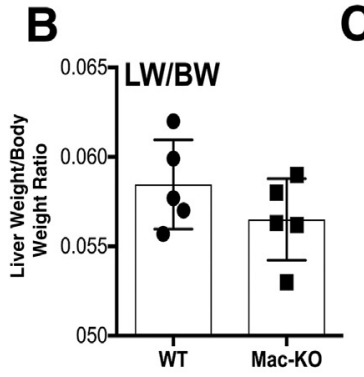
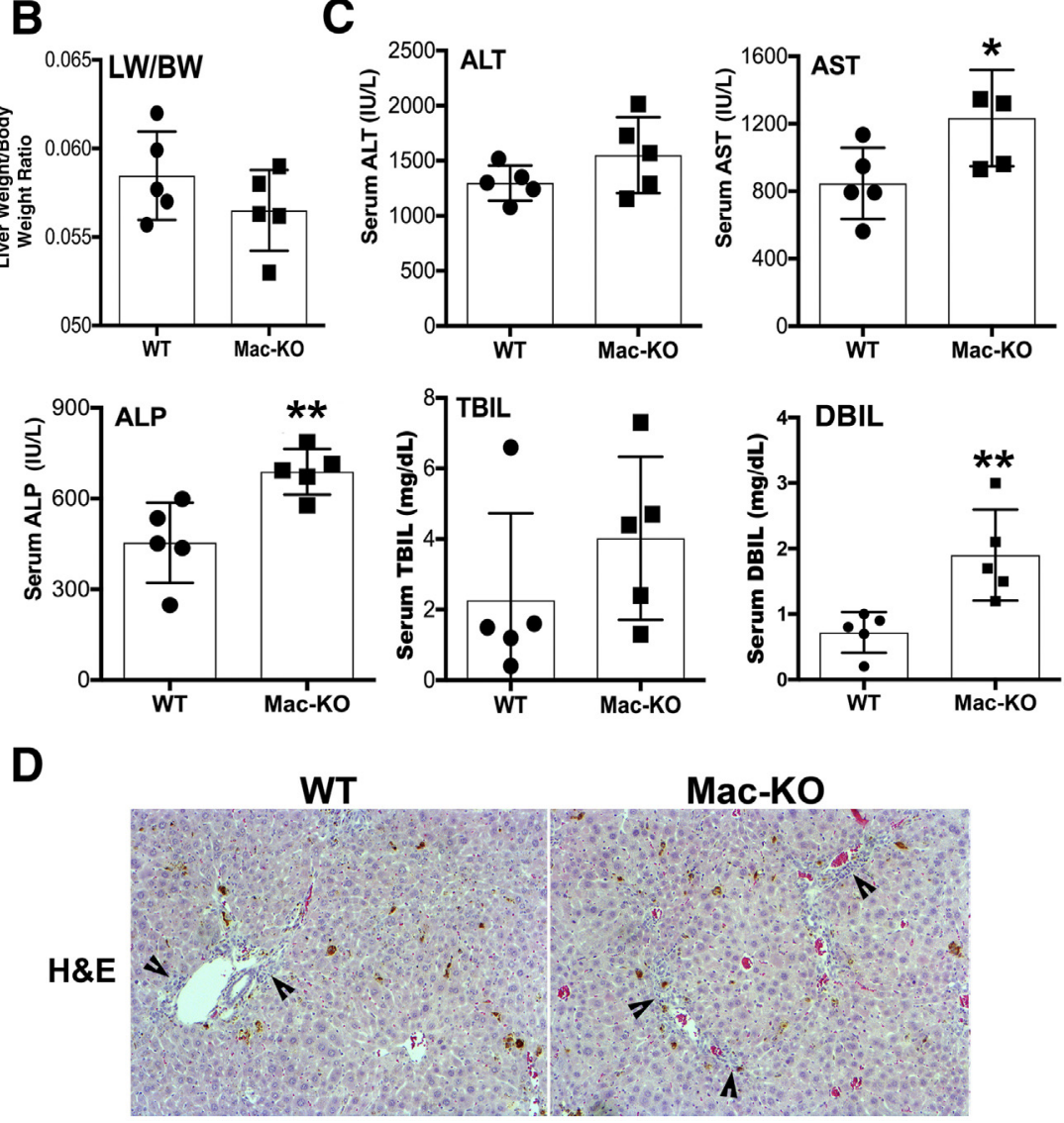

Figure 3 Evidence of increased hepatobiliary damage in Mac-KO mice after 14 days of DDC diet. A: Schematic depicting DDC diet protocol used in the study. B: No change in liver weight/body weight (LW/BW) ratio between Mac-KO and WT mice after feeding DDC diet for 14 days, but trend toward reduced liver size in Mac-KO mice. C: Significant increases in serum aspartate aminotransferase (AST; normal, 30 to $50 \mathrm{IU} / \mathrm{L}$ ), alkaline phosphatase (ALP; normal, 20 to $100 \mathrm{IU} / \mathrm{L}$ ), and direct bilirubin (DBIL; normal, 0 to $0.2 \mathrm{mg} / \mathrm{dL}$ ) in Mac-KO compared with WT after 14 days of DDC diet. D: Representative hematoxylin and eosin (H\&E) images from DDC-treated Mac-KO and WT livers showing evidence of more pronounced ductular reaction and periportal inflammation (arrowheads) in Mac-KO mice. Data are expressed as means \pm SD. ${ }^{*} P<0.05,{ }^{*} P<0.01$. Original magnification, $\times 100$ (D). ALT, alanine aminotransferase; TBIL, total bilirubin.
PCR with denaturation at $95^{\circ} \mathrm{C}$ for 15 seconds and annealing and extension at $60^{\circ} \mathrm{C}$ for 1 minute for 40 cycles was conducted in a CFX96 (Bio-Rad). Expression of target genes was calculated by the ${ }^{\Delta \Delta} \mathrm{Ct}$ method using threshold cycles for $\beta$-actin and $\beta 2$-microglobulin as normalization references. RNA without reverse transcriptase served as a negative control. The primer sequences for all Wnt primers have been published previously, ${ }^{18}$ and additional primers used in the current study are listed in Table 1.

\section{Statistical Analysis}

All experiments were performed with four to five animals, and representative data are presented. Real-time quantitative RT-PCR analysis was performed on $n \geq 3$ mice done in triplicate. All statistics were performed with Prism 6 software version 7.0 (GraphPad Software Inc., La Jolla, CA). Densitometric analysis was performed using Image Pro Plus software version 7 (Media Cybernetics, Rockville, MD).
Statistical differences were assessed with Welch's $t$-test, and $P<0.05$ was considered statistically significant.

\section{Results}

\section{DDC Diet Causes Altered Wnt Expression in Macrophages}

To elucidate the role of macrophage-derived Wnts and their overall impact on DDC-induced cholestatic liver injury, the impact of DDC diet feeding was first examined on Wnt expression. Previously, Wnt7a, Wnt7b, and Wnt10a expression levels were shown to be up-regulated in livers of DDCfed mice for 14 to 28 days. ${ }^{18} \mathrm{~F} 4 / 80^{+}$macrophages were isolated using a magnetic bead isolation protocol $(\mathrm{F} 4 /$ 80-magnetic-activated cell sorting) from the nonparenchymal cell fractions of livers from normal mice fed either a basal or DDC diet for 14 days $(n=2$ mice per condition) (Figure 1A). The purity of the pooled macrophage 
fractions was confirmed using cell-type-specific gene expression analysis. Using marker genes for hepatocytes (Alb), macrophages (CD68 and lysozyme), and endothelial cells (Tie2), $>98 \%$ purity of the $\mathrm{F} 4 / 80^{+}$macrophages was confirmed by both inclusion of positive markers (CD68 and lysozyme) and exclusion of negative markers (albumin and Tie2) via real-time quantitative RT-PCR (Figure 1B). The mRNA expression of several Wnt genes, which revealed a notable up-regulation of Wnt11 in DDC-fed mice, was next assessed; Wnt7b and Wnt10a showed variable increases (Figure 1C). In fact, differential expression was noted in most Wht genes analyzed in macrophages isolated from mice after DDC diet compared with basal diet (Figure 1C). These data indicate that DDC induced notable alterations in the expression of Wnts in macrophages and that macrophage-derived Wnts may be playing an important role in DDC diet-induced liver pathology.

\section{Confirmation of Macrophage-Specific Loss of Wntless Expression}

To assess the role of macrophages as the source of the entire Wnt repertoire, all Wnt secretion from macrophages was eliminated by crossing LyzM Cre ${ }^{+/-}$mice with Wntless/Evi $(W l s)$ Loxp $^{+/+}$mice to generate Mac-KO mice. Parenchymal cells and nonparenchymal cells were separated by collagenase perfusion from Mac-KO mice and wild-type (WT) littermate controls. F4/80 $0^{+}$macrophages and CD31 $1^{+}$ endothelial cells were then isolated from the nonparenchymal fractions by magnetic bead isolation protocol using $\mathrm{F}_{4} / 80^{-}$and $\mathrm{CD} 31-$ magnetic-activated cell sorting beads. PCR analyses of macrophage DNA from Mac-KO mice showed the deleted allele of Wls, confirming successful recombination in the macrophages (Figure 1D). Furthermore, the enriched macrophage fraction was assessed for mRNA expression of Wls, which was diminished in Mac-KO (Figure 1E), as also described previously. ${ }^{12}$

Last, bone marrow progenitor cells were isolated from Mac-KO or WT mice fed chow diet and differentiated into mature $\mathrm{M}_{0}$ macrophages (BMDMs) in vitro, as described in Materials and Methods. Gene expression analysis for Wls and a panel of Wnt ligands showed a significant loss of Wls expression in the Mac-KO, as expected, as well as a remarkably different $W n t$ gene expression profile compared with WT (Figure 2). All of the Wnt ligands analyzed (total 16) were detected in the BMDMs. Several Wnts (Wnt1, Wnt2, Wnt2b, Wnt3, Wnt4, Wnt5b, Wnt6, Wnt7a, Wnt7b, Wnt8a, Wnt9a, Wnt9b, Wnt10a, Wnt11, and Wnt16) were upregulated manyfold in Mac-KO BMDMs compared with WT BMDMs (Figure 2). Wnt5a and Wnt $10 b$ were notably down-regulated, whereas there was no change in the expression of Wnt $8 b$ (Figure 2). These changes in expression of many Wnt genes, triggered by the loss of Wls, suggest that macrophages are an active and significant source of Wnt ligands, and Wnt secretion by macrophages regulates Wnt gene expression in these same cells through positive and/or negative feedback in an autocrine or paracrine manner.

\section{Evidence of Overall Enhanced Hepatic Injury and} Decreased Hepatic Repair in the Mac-KO Mice Fed DDC Diet

Two-month-old Mac-KO and WT mice were fed the DDC diet for 14 days (Figure 3). There was no difference in the gross appearance of livers between the two groups, and although the liver weight/body weight ratios were comparable, a trend toward smaller livers was observed in the Mac-KO mice (Figure 3). Serum biochemistry analyses showed significantly higher levels of aspartate aminotransferase, alkaline phosphatase, and direct bilirubin in the Mac-KO mice, whereas total bilirubin and alanine aminotransferase tended to be higher but did not show high significance between Mac-KO and WT mice (Figure 1D). Histologic analysis indicated that, as expected, DDC injury induces prominent ductular reaction and periportal inflammation, which was apparent in both WT and Mac-KO mice
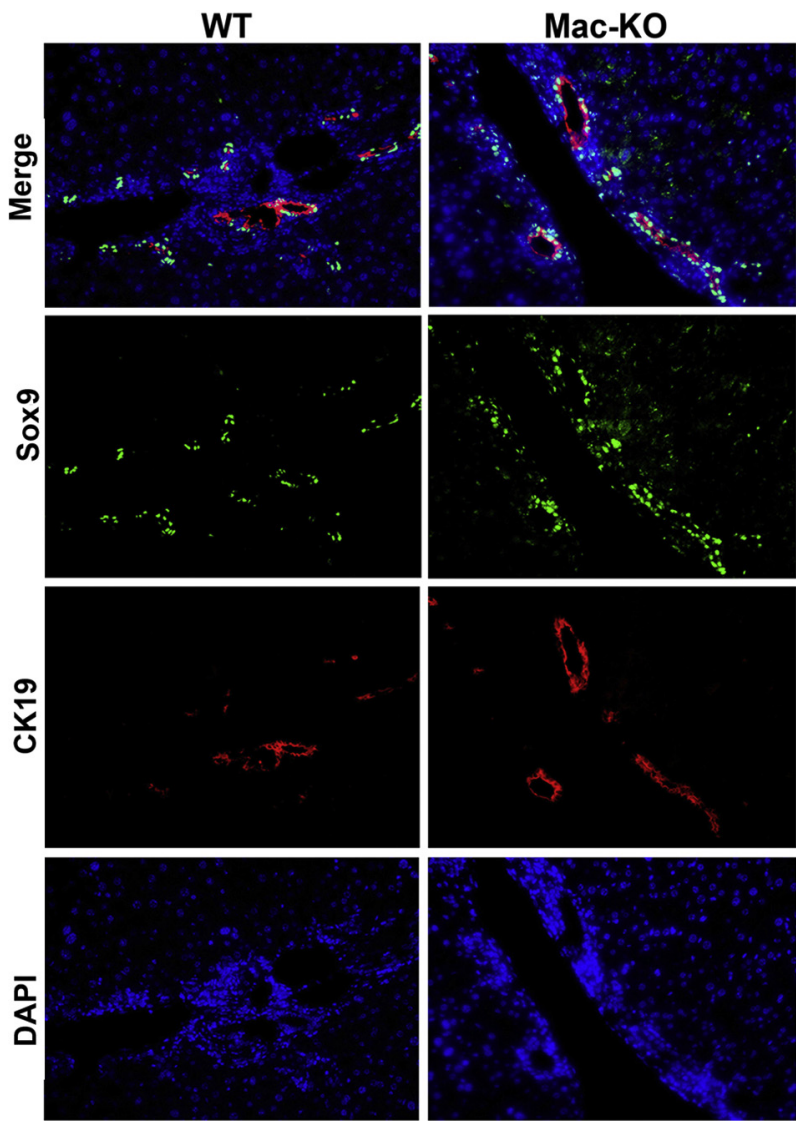

Figure 4 Immunofluorescence analysis verifies increased ductular reaction in the Mac-KO mice after 14 days of DDC diet. Immunofluorescence staining was performed for transcription factor SOX-9 (Sox9) and cytokeratin 19 (CK19) to label ductular reaction, which is enhanced in the Mac-KO mice compared with WT mice after 14 days of DDC diet. DAPI was used as nuclear counterstain. Original magnification, $\times 200$. 
A
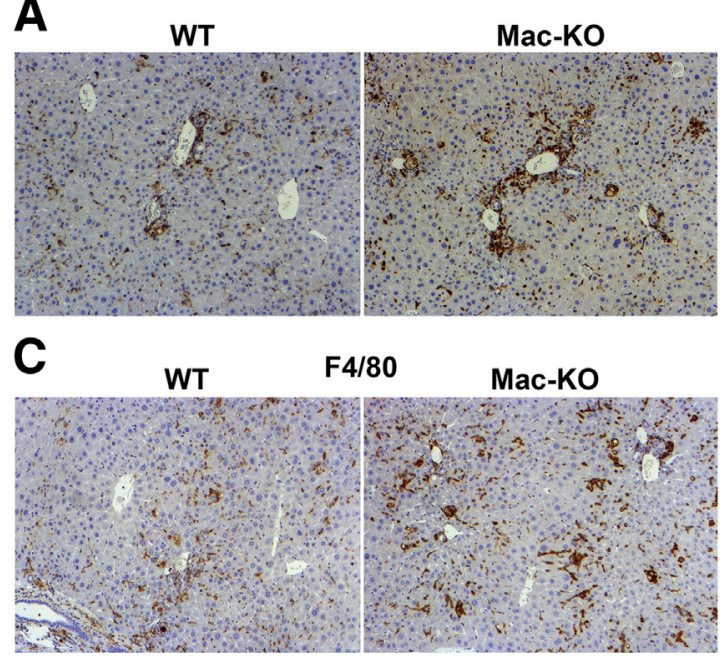

E
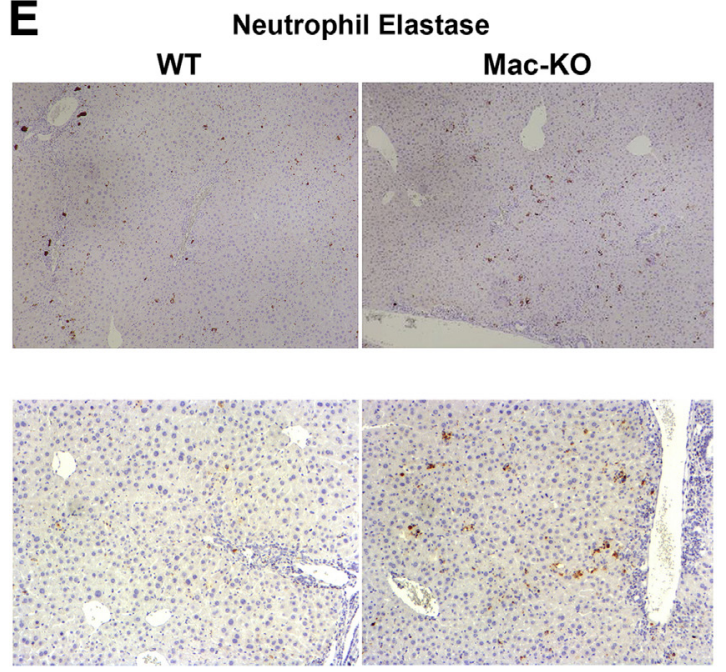

B

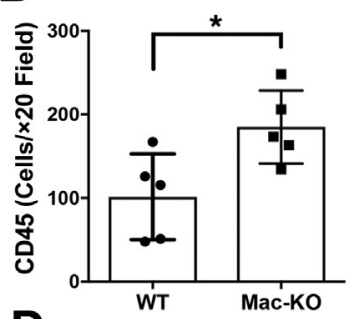

D
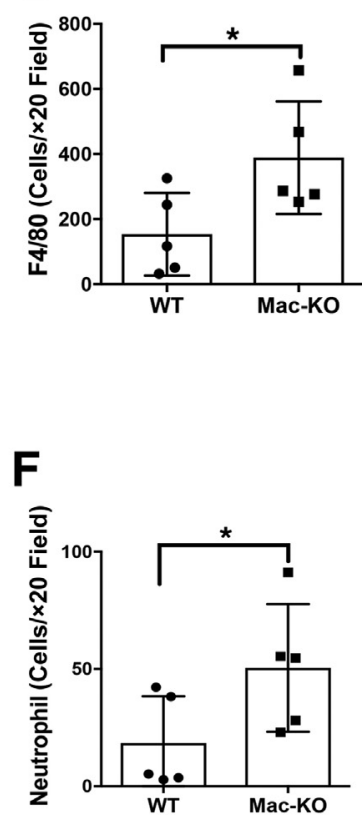

Figure 5 Increased immune response in Mac-KO mice compared with WT mice after 14 days of DDC feeding. A: Immunohistochemistry (IHC) for CD45 shows more positive cells in Mac-KO than WT mice, supporting enhanced overall inflammation in this group. B: Quantification of the number of CD45positive cells per $\times 20$ field shows a significant increase in the number of positive cells in Mac-KO mice after 14 days of DDC compared with WT mice. C: IHC for $\mathrm{F} 4 / 80$ shows more positive cells in Mac-KO than WT mice, depicting greater number of macrophages in this group. D: Quantification of the number of F4/80positive cells per $\times 20$ field shows a significant increase in the number of positive cells in Mac-KO mice after 14 days of DDC compared with WT mice. E: IHC for neutrophil elastase shows greater number of positive cells in Mac-KO livers than WT livers in response to DDC exposure for 14 days. F: Quantification of the number of neutrophil elastase-positive cells per $\times 20$ field shows a significant increase in the number of positive cells in Mac-KO mice after 14 days of DDC compared with WT mice. Data are expressed as means \pm SD. ${ }^{*} P<0.05$. Original magnifications: $\times 100(\mathbf{A}$, C, and $E$, bottom panels); $\times 50$ (E, top panels). by hematoxylin and eosin stain, although a more pronounced ductular reaction, inflammation, and altered hepatic architecture were seen in the Mac-KO mice (Figure 3).

To verify changes in ductular reaction, which is an indicator of DDC-induced hepatobiliary injury, immunofluorescence staining was performed for CK19 and Sox9. MacKO mice showed greater CK19- and Sox9-positive ductular cells in comparison to WT mice, thus confirming histologic findings (Figure 4).

To verify changes in inflammation, it was then investigated whether loss of Wnt secretion from macrophages exacerbated the inflammatory response. DDC-diet-fed Mac-KO mice showed an overall increase in the number of $\mathrm{CD} 45^{+}$leukocytes (Figure 5A). On quantification, this was significantly different from the WT mice (Figure 5B). To specifically examine any differences in the number of macrophages, IHC was performed for F4/80 in the Mac-KO and WT mice after DDC diet (Figure 5C). A significant increase in the number of macrophages was evident in the Mac-KO mice after DDC (Figure 5D). Last, overall neutrophil infiltration was determined in the WT versus Mac-KO mice after 14 days of DDC diet (Figure 5E). A greater and significant increase in neutrophil recruitment was observed in the Mac-KO mice on DDC diet (Figure 5F). These findings suggest that loss of Wnt secretion from macrophages promoted hepatic inflammatory milieu and may be contributing to overall disease pathogenesis after DDC diet.

Because increased ductular reaction and inflammation can be associated with increased fibrosis, cell death, and compensatory hepatocyte proliferation, each of these attributes was next examined. Sirius Red staining was used to determine overall collagen deposition in livers of WT and Mac-KO mice after 14 days of DDC. Comparable staining for Sirius Red was evident in the two groups (Figure 6A) and verified quantitatively (Figure 6B). Likewise, staining for the activated myofibroblast marker, $\alpha$-smooth muscle actin, showed comparable positivity in the two groups (Figure 6A) and was confirmed by densitometric analysis (Figure 6B). 

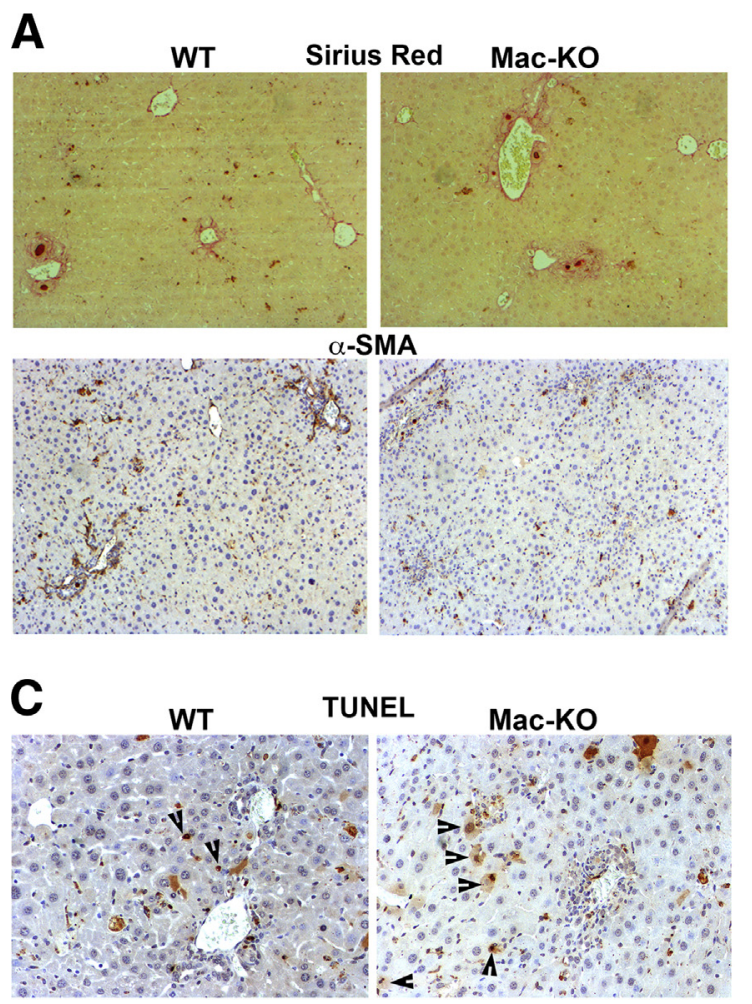

E

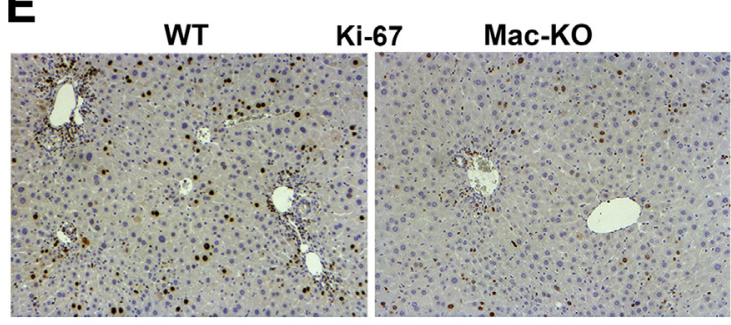

B
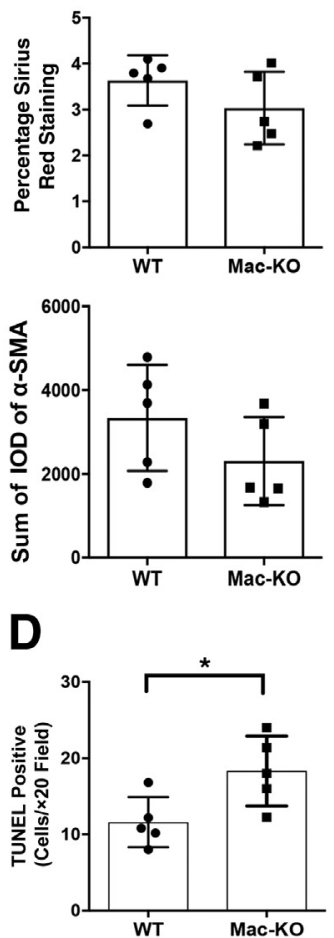

$\mathbf{F}$

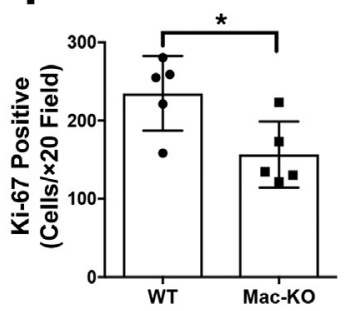

Figure 6 Increased cell death, decreased proliferation, but comparable fibrosis in Mac-KO versus WT mice after 14 days of DDC diet. A: Staining for Sirius Red (top panels) shows comparable positivity in the Mac-KO and WT mice after 14 days of DDC diet. Immunohistochemistry for $\alpha$-smooth muscle actin ( $\alpha$ SMA; bottom panels) to identify activated myofibroblasts also shows comparable numbers of positive cells in the Mac-KO and WT mice after 14 days of DDC diet. B: Quantification of both Sirius Red staining and number of $\alpha$-SMA-positive cells in the Mac-KO and WT mice after 14 days of DDC diet shows insignificant differences between the two groups. C: Increased terminal deoxynucleotidyl transferase-mediated dUTP nick-end labeling (TUNEL)-positive hepatocytes (arrowheads) in Mac-KO compared with WT mice after 14 days of DDC diet. D: Quantification of the number of TUNEL-positive cells per $\times 20$ field shows a significant increase in the number of positive cells in Mac-KO mice after 14 days of DDC compared with WT mice. E: Decreased Ki-67-positive hepatocytes in Mac-KO compared with WT mice denotes fewer proliferating cells in Mac-KO mice after 14 days of DDC. F: Quantification of the number of Ki-67-positive cells per $\times 20$ field shows a significant increase in the number of positive cells in Mac-KO mice after 14 days of DDC compared with WT mice. Data are expressed as means \pm SD. $n=3$ mice. ${ }^{*} P<0.05$. Original magnifications: $\times 100(\mathbf{A}$ and $\mathbf{E}) ; \times 200$ (C). IOD, integrated optical density.
DDC diet can lead to cell death due to bile acids and inflammation. To address if hepatocyte cell survival is affected differentially when macrophages cannot secrete Wnts, terminal deoxynucleotidyl transferase-mediated dUTP nick-end labeling staining was performed on the livers from Mac-KO and WT mice after 14 days of DDC (Figure 6C). A notable increase in the number of terminal deoxynucleotidyl transferase-mediated dUTP nick-end labeling-positive hepatocytes was evident in Mac-KO mice, verifying increased hepatocyte death (Figure 6D). Furthermore, in response to DDC-induced injury, the hepatic repair response occurs in the form of enhanced hepatocyte proliferation, which can be detected by IHC for a proliferation marker like Ki-67. As expected, several hepatocytes in WT livers show increased staining for Ki-67; however, relatively fewer hepatocytes show Ki-67 positivity in Mac-KO livers after 14 days of DDC (Figure 6E). On quantification, this difference was statistically significant, suggesting a compromise in hepatic repair in the Mac-KO mice after DDC (Figure 6F).

\section{Decreased $\beta$-Catenin Activation in Mac-KO Mice May Compromise Hepatocyte Proliferation after DDC Injury}

Macrophages play an important role as a source of Wnts for regulating hepatocyte proliferation or fate of progenitors in various forms of hepatobiliary repair, including after partial hepatectomy. $^{12,13}$ To investigate whether abolishing $\mathrm{Wnt}$ secretion from monocytes and macrophages after DDC diet would affect $\beta$-catenin activation in hepatocytes that could result in an impaired regenerative response, IHC and Western blot analyses were performed for $\beta$-catenin targets like cyclin-D1 and GS. IHC for GS showed some irregular staining in zone-3 in Mac-KO compared with WT mice after DDC (Figure 7A). Quantification of GS staining showed a significant decrease in overall GS positivity in Mac-KO mice after DDC (Figure 7B). Likewise, number of cyclinD1-positive hepatocytes appeared to be fewer, albeit marginally, in Mac-KO mice after DDC when compared with WT mice (Figure 7C). Densitometry verified this decrease to be significant (Figure 7D). 

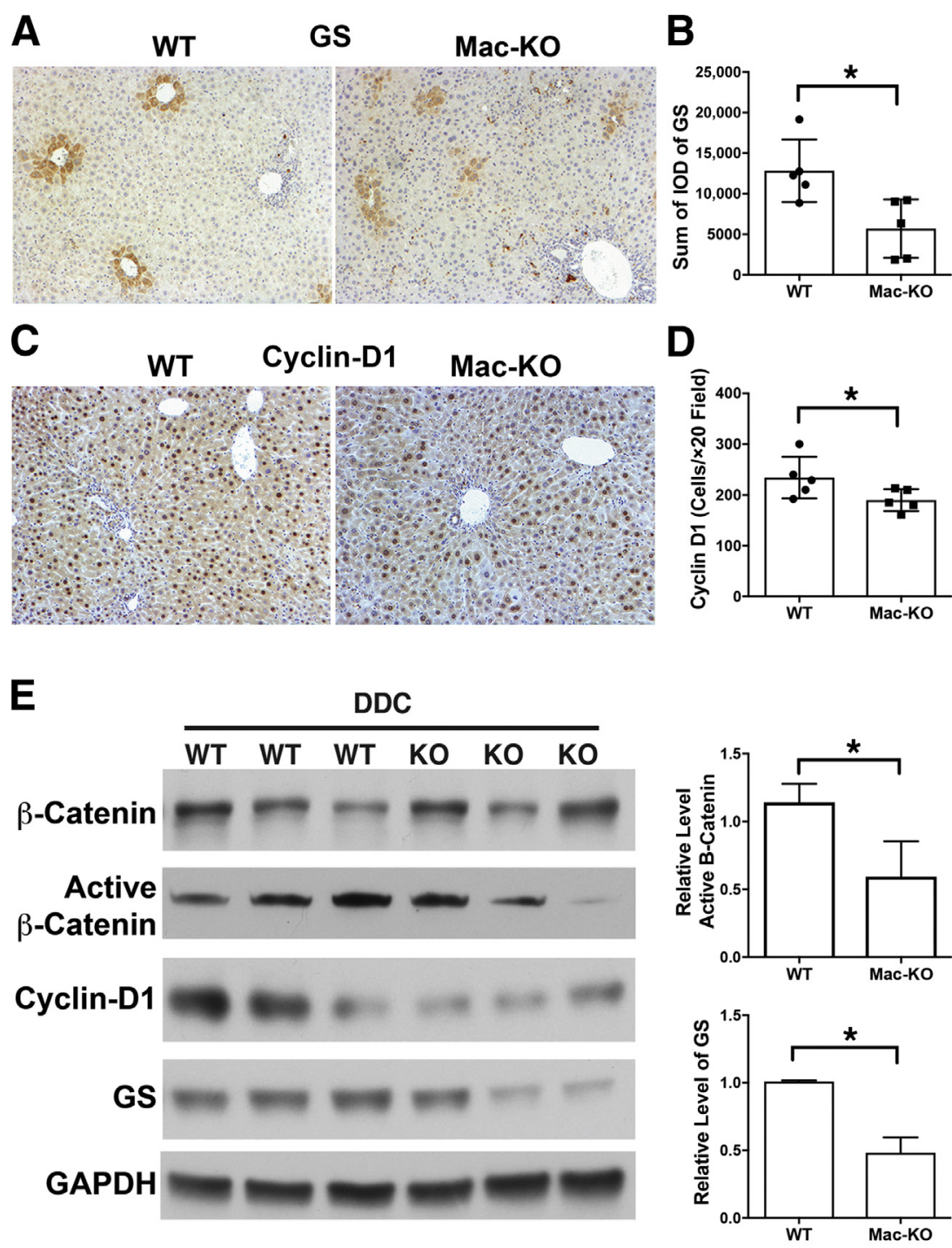

Figure 7 Decreased $\beta$-catenin activation in MacKO mice after 14 days of DDC diet. A: Immunohistochemistry (IHC) for glutamine synthase (GS) shows positive hepatocytes located at pericentral areas in both WT and Mac-KO mice, but with considerably less regularity and intensity in the Mac-KO mice after 14 days of DDC. B: Quantification of GS staining shows a significant decrease in the number of positive area in the Mac-KO mice after 14 days of DDC compared with WT mice. C: IHC for cyclin-D1 shows relatively fewer, albeit marginally, in the Mac-KO compared with WT mice after 14 days of DDC. D: Quantification of the number of cyclin-D1-positive cells per $\times 20$ field shows a significant decrease in the number of positive cells in Mac-KO mice after 14 days of DDC compared with WT mice. E: Western blot analyses of liver tissue for $\beta$-catenin, active $\beta$-catenin, GS, and cyclin-D1 shows decreases in active $\beta$-catenin and confirms reduced GS and cyclin-D1 after 14 days of DDC diet in Mac-KO mice. Glyceraldehyde-3-phosphate dehydrogenase (GAPDH) verified protein loading. Although cyclin-D1 decrease is obvious, densitometry showed a significant decrease in the levels of both active $\beta$ catenin as well as GS in Mac-KO compared with WT mice. Liver lysates from three mice per genotype were used for this analysis. Data are expressed as means \pm SD. $n=3$ mice. ${ }^{*} P<0.05$. Original magnification, $\times 100($ A and C). IOD, integrated optical density.
For a more accurate quantitative assessment, Western blot analysis was performed with liver lysates from DDCdiet-fed WT and Mac-KO mice. Although total $\beta$-catenin levels were not different between the two groups, active $\beta$ catenin levels were reduced in the Mac-KO mice (Figure 7E). Densitometry verified this decrease to be significant. Cyclin-D1 levels were also notably reduced in the Mac-KO livers (Figure 7E). Likewise, GS levels were significantly decreased after DDC in Mac-KO compared with WT mice (Figure 7E). Altogether, these findings suggest that loss of Wnt secretion from macrophages negatively affected proregenerative $\beta$-catenin signaling in hepatocytes, and a compromise in repair may also be contributing to overall enhanced hepatobiliary injury after DDC.

\section{Increased Inflammatory Chemokines and Cytokines in Mac-KO Mice after DDC}

Because DDC diet led to increased $\mathrm{CD} 45^{+}$leukocytes, neutrophils, and $\mathrm{F} 4 / 80^{+}$macrophages in Mac-KO mice, it was next investigated if expression of chemokines that regulate the recruitment of such inflammatory cells in the liver are altered between the two groups. Gene expression analysis of liver mRNA from the Mac-KO mice after 14 days of DDC diet compared with control diet showed significant increases in chemokines ( $\mathrm{Ccl} 2 \mathrm{CCl} 3$, and $\mathrm{CxCL1}$ ); E-selectin (CD26E), a cell adhesion molecule that regulates inflammatory cell rolling and migration; and inflammatory cytokines (Il6 and Tnfa) (Figure 8). Nos2 (M1 macrophage marker) was also elevated in Mac-KO mice (Figure 8). These findings reveal a coincident increase in proinflammatory cytokines and chemokines in Mac-KO mice after DDC injury, suggesting their contribution to enhanced inflammation and hepatobiliary injury.

\section{Myeloid-Specific Loss of Wnt Secretion Affects Macrophage Plasticity}

Because an increase was identified in M1 marker Nos2 in Mac-KO mice after DDC diet, and several studies have 

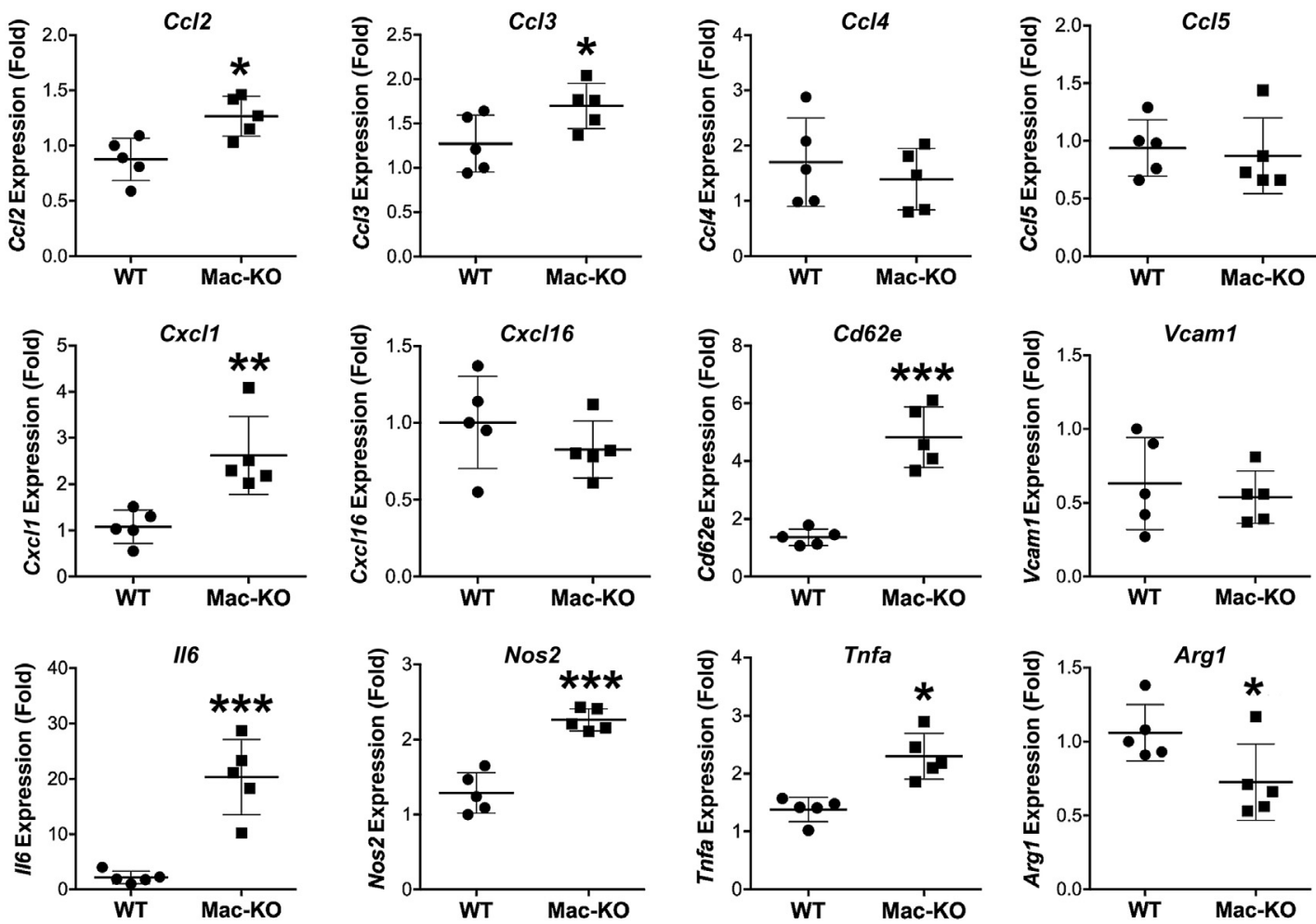

Figure 8 Increased expression of proinflammatory cytokines and chemokines in livers of Mac-KO than WT mice after 14 days of feeding DDC diet. Gene expression analysis using real-time quantitative RT-PCR reveals a significant increase in expression of $C C l 2, C C l 3, C x c l 1, C d 26 e, I l 6$, Nos2, and Tnfa and decreased expression of Arg1 in Mac-K0 when compared with WT mice. Data are expressed as relative expression, fold change. ${ }^{*} P<0.05$, ${ }^{* *} P<0.01$, and $* * * P<0.001$. VCAM, vascular cell adhesion molecule.

suggested macrophage polarization to $\mathrm{M} 1$ regulates inflammatory and wound healing responses, it was next investigated if loss of Wnt secretion from macrophages showed an effect on basal macrophage plasticity. BMDMs from basal-diet-fed Mac-KO and WT mice were isolated and differentiated in vitro, as above. Gene expression analyses of macrophage polarization marker genes revealed elevated expression of M1 markers (Nos2, IIllb, Ccl2, and $\mathrm{Tnfa}$ ), whereas some M2 markers (Mrc and $\mathrm{Yml}$ ) were coincidentally decreased in Mac-KO BMDMs (Figure 9A). Next, it was investigated whether macrophages in Mac-KO mice after DDC-diet-induced hepatic injury showed differential macrophage polarization. Using F4/80, macrophages were isolated from DDC-fed WT and Mac-KO mice by fluorescence-activated cell sorting, as described in Materials and Methods. Notably, liver F4/80 $0^{+}$macrophages showed significantly higher expression of Nos 2 in Mac-KO mice compared to WT mice, whereas Argl levels were comparable (Figure 9B). All together, these findings suggest that macrophage-specific Wls loss, which prevents Wnt secretion from these cells, promotes a proinflammatory M1 macrophage phenotype, both basally and after hepatic injury; hence, Wnt secretion from macrophages may in fact be largely protective and proregenerative in the DDC diet model.

\section{Discussion}

Variable and multifunctional aspects of macrophage biology have revealed that they contribute to acute and chronic inflammation. ${ }^{23,24}$ Moreover, macrophages contribute to tissue repair and protection from infection. Wnt secretion by macrophages promotes intestinal crypt regeneration after radiation injury. ${ }^{25}$ Moreover, macrophages may be one of the sources of stromal Wnts in crypt cells of the small intestine, and macrophage-derived Wnts have been reported to have a significant role in tissue repair and regeneration. ${ }^{26,27}$ Recent studies showed that macrophage-derived Wnt7b was crucial for epithelial regeneration in kidney injury. ${ }^{28}$ Macrophage-derived Wnts have also been shown to effect angiogenesis by regulating vascular endothelial growth factor signaling in vascular endothelial cells. ${ }^{27}$ Porcupine deletion, that results in loss of Wnt lipidation and subsequent Wnt secretion, has been shown to affect intestinal epithelial regeneration after radiation injury. Thus, there appears to be a paradigm in which macrophage-derived Wnts deliver spatial and temporal signals to promote regeneration after tissue injury. However, the molecular mechanisms regulating macrophage functions in inflammation, tissue repair, and fibrosis are newly emerging. ${ }^{29,30}$ 
Bone Marrow-Derived Macrophages

Nos2

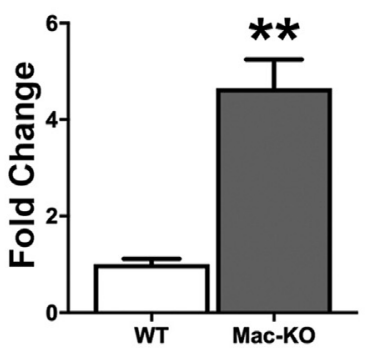

$\operatorname{Arg} 1$

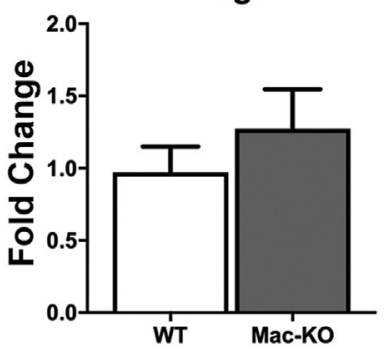

116

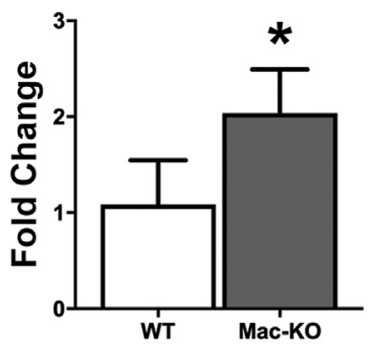

Mrc

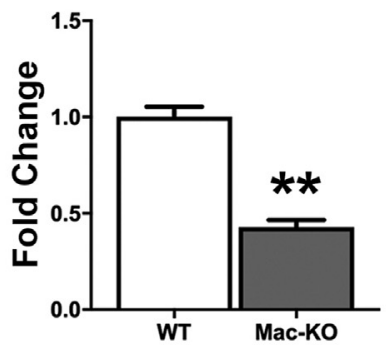

B

Liver F4/80+ Macrophages
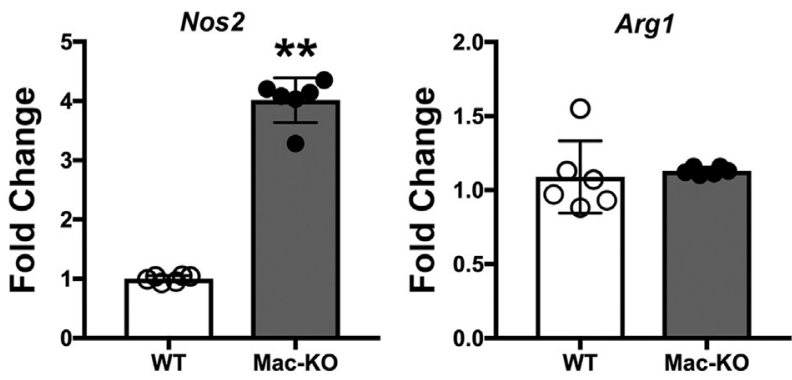

Macrophages contribute to liver inflammation, fibrosis, and regeneration via multiple mechanisms. Inflammatory, bone marrow-derived monocytes infiltrate the liver in response to injury, where they are dynamically reprogrammed, depending on the nature and chronicity of the injury.,31-33 Macrophages are among the earliest responders to liver injury, having roles in phagocytosis of apoptotic and necrotic cells and releasing soluble mediators, such as tumor necrosis factor and IL-6, which orchestrate inflammatory and profibrogenic responses to chronic injury. Macrophages are also prominent components of the hepatic progenitor cell niche, which is closely associated with liver fibrogenesis and repair ${ }^{3,7}$; the fate relationships among hepatocytes, cholangiocytes, and hepatic progenitor cells and the contribution of hepatic progenitor cells to liver fibrosis and regeneration are controversial, ${ }^{34,35}$ and the factors determining their activation and differentiation are not well understood. Wnt proteins, potentially derived from macrophages, have been suggested to promote liver regeneration

Cc/2

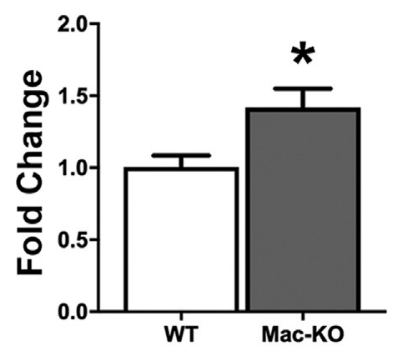

Mgl1
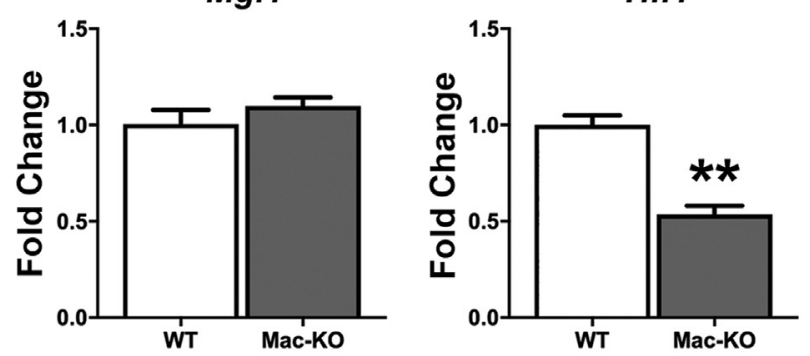

Figure 9 Myeloid-specific loss of Wnt secretion promotes M1 macrophage phenotype. A: Bone marrow-derived macrophages from Mac-K0 mice show significantly higher mRNA expression of Nos2, Il6, $\mathrm{Ccl} 2$, and $\operatorname{Tnfa}$ (M1 markers) and significantly decreased expression of Mrc and $Y_{m 1}$ (M2 markers) than WT mice, suggesting M1 polarization in Mac-KO mice at baseline without DDC exposure. Data presented as relative expression, fold change. Three mice from each genotype were used. B: Significantly increased expression of M1 marker Nos2 in F4/ 80-positive macrophages isolated from livers of Mac-KO compared with WT mice fed 14 days of DDC diet. No change in Arg1 expression is observed between the two groups. Data are expressed as relative expression, fold change. ${ }^{*} P<0.05,{ }^{*} P<0.01$.

by driving differentiation of hepatocyte progenitors, ${ }^{13}$ which could theoretically ameliorate liver fibrosis by promoting repair. Wnt proteins, however, constitute a large family of proteins that have variously attributed profibrogenic and antifibrogenic properties, ${ }^{36,37}$ which likely have multiple potential target cells and mechanisms of action during chronic liver disease. Using a choline-deficient-0.5\% ethionine-supplemented diet model, liver progenitor cells have also been shown to be dependent on macrophages for their invasiveness and recruitment. ${ }^{9,38}$

To further our understanding of the role of macrophages as the source of Wnts in hepatobiliary injury and repair, the DDC diet model and mice lacking the ability to secrete all Wnts from all myeloid cells, by virtue of LysM-Cre knockout of Wls, a protein absolutely essential and specific for all Wnt secretion from a cell, ${ }^{39}$ were used. In this study, loss of Wnt secretion by macrophages promoted DDCdiet-induced hepatobiliary injury through two major mechanisms. Prevention of Wnt release from macrophages 
resulted in increased recruitment of inflammatory cells and promoted proinflammatory M1 macrophages and at the same time compromised hepatobiliary repair by diminishing hepatocyte proliferation.

This study suggests that macrophage-derived Wnts facilitate hepatocyte proliferation after DDC-induced injury, which partially explains the increased hepatic damage in Mac-KO mice. Indeed, such a role for macrophage-derived Wnts has been described during acute liver injury, such as hepatectomy, where they promote hepatocyte proliferation. ${ }^{12}$ Likewise, in chronic liver injury, they promote reprogramming of progenitor cells. ${ }^{13,40}$ Overall, our current study suggests that Wnts produced by macrophages may normally be promoting a more proregenerative M2 macrophage phenotype and facilitating repair efforts.

These findings also show that loss of Wnt secretion by myeloid cells, including monocytes and macrophages, promoted proinflammatory M1 macrophage phenotype. Increased injury in Mac-KO mice after DDC was associated with enhanced inflammation, as seen by increased infiltration of macrophages and neutrophils. The current study suggests that preventing Wnt secretion by macrophages makes these cells more prone to exhibit a proinflammatory M1 phenotype and induce recruitment of neutrophils causing more hepatic injury. Macrophage polarization was analyzed, and it was shown that after 2 weeks of DDC diet, the liver macrophages are predominantly M1 rather than M2. The mechanisms contributing to the elevated M1 macrophage response need further investigation.

Which Wnts may be promoting regeneration and repair and/or driving the M2 over M1 macrophage phenotype in the context of DDC injury remains unclear; however, when liver macrophages were isolated by liver perfusion and cell separation techniques, Wnt11 was notably increased after the administration of DDC diet. Wnt11 is known to be induced by transforming growth factor- $\beta$ and mediates mesenchymal transition of renal epithelial cells via noncanonical Wnt signaling. ${ }^{41}$ Wnt11 is also reported to inhibit the invasion of bacteria in an enteritis model. ${ }^{42} \mathrm{Wnt} 7 \mathrm{~b}$ and Wnt10a were also up-regulated, although there was variability in their expression. Wnt7b secretion by kidney macrophages induces repair after kidney injury. ${ }^{28} \mathrm{~A}$ recent study has also shown positive impact of Wnt7a, Wnt7b, and Wnt10a on cholangiocyte proliferation and hepatocyte-tobiliary transdifferentiation after DDC injury. ${ }^{18}$ In that study, hepatocytes and cholangiocytes were the major source of these Wnts. This study shows that Wnt7b and Wnt10a after DDC injury may also be arising from macrophages, whereas Wnt11 is more exclusive to macrophages. Future genetic studies will be essential to clarify the roles of specific Wnts in DDC and other liver injury models.

In conclusion, Wnt secretion from macrophages is important for hepatobiliary repair in DDC-induced injury, as shown by deletion of Wls in these cells, which promoted an enhanced immune response and M1 polarization of macrophages and simultaneously compromised hepatocyte proliferation.

\section{Supplemental Data}

Supplemental material for this article can be found at https://doi.org/10.1016/j.ajpath.2018.11.010.

\section{References}

1. Monga SP: beta-Catenin signaling and roles in liver homeostasis, injury, and tumorigenesis. Gastroenterology 2015, 148:1294-1310

2. Iredale JP, Thompson A, Henderson NC: Extracellular matrix degradation in liver fibrosis: biochemistry and regulation. Biochim Biophys Acta 2013, 1832:876-883

3. Williams MJ, Clouston AD, Forbes SJ: Links between hepatic fibrosis, ductular reaction, and progenitor cell expansion. Gastroenterology 2014, 146:349-356

4. Gouw AS, Clouston AD, Theise ND: Ductular reactions in human liver: diversity at the interface. Hepatology 2011, 54:1853-1863

5. Duffield JS, Forbes SJ, Constandinou CM, Clay S, Partolina M, Vuthoori S, Wu S, Lang R, Iredale JP: Selective depletion of macrophages reveals distinct, opposing roles during liver injury and repair. J Clin Invest 2005, 115:56-65

6. Lorenzini S, Bird TG, Boulter L, Bellamy C, Samuel K, Aucott R, Clayton E, Andreone P, Bernardi M, Golding M, Alison MR, Iredale JP, Forbes SJ: Characterisation of a stereotypical cellular and extracellular adult liver progenitor cell niche in rodents and diseased human liver. Gut 2010, 59:645-654

7. Gadd VL, Melino M, Roy S, Horsfall L, O'Rourke P, Williams MR, Irvine KM, Sweet MJ, Jonsson JR, Clouston AD, Powell EE: Portal, but not lobular, macrophages express matrix metalloproteinase-9: association with the ductular reaction and fibrosis in chronic hepatitis $\mathrm{C}$. Liver Int 2013, 33:569-579

8. Bird TG, Lu WY, Boulter L, Gordon-Keylock S, Ridgway RA, Williams MJ, Taube J, Thomas JA, Wojtacha D, Gambardella A, Sansom OJ, Iredale JP, Forbes SJ: Bone marrow injection stimulates hepatic ductular reactions in the absence of injury via macrophagemediated TWEAK signaling. Proc Natl Acad Sci U S A 2013, 110: 6542-6547

9. Van Hul N, Lanthier N, Espanol Suner R, Abarca Quinones J, van Rooijen N, Leclercq I: Kupffer cells influence parenchymal invasion and phenotypic orientation, but not the proliferation, of liver progenitor cells in a murine model of liver injury. Am J Pathol 2011, 179: $1839-1850$

10. Kantari-Mimoun C, Castells M, Klose R, Meinecke AK, Lemberger UJ, Rautou PE, Pinot-Roussel H, Badoual C, Schrodter K, Osterreicher CH, Fandrey J, Stockmann C: Resolution of liver fibrosis requires myeloid cell-driven sinusoidal angiogenesis. Hepatology 2015, 61:2042-2055

11. Nejak-Bowen KN, Monga SP: Beta-catenin signaling, liver regeneration and hepatocellular cancer: sorting the good from the bad. Semin Cancer Biol 2011, 21:44-58

12. Yang J, Mowry LE, Nejak-Bowen KN, Okabe H, Diegel CR, Lang RA, Williams BO, Monga SP: beta-Catenin signaling in murine liver zonation and regeneration: a Wnt-Wnt situation! Hepatology 2014, 60:964-976

13. Boulter L, Govaere O, Bird TG, Radulescu S, Ramachandran P, Pellicoro A, Ridgway RA, Seo SS, Spee B, Van Rooijen N, Sansom OJ, Iredale JP, Lowell S, Roskams T, Forbes SJ: Macrophagederived Wnt opposes Notch signaling to specify hepatic progenitor cell fate in chronic liver disease. Nat Med 2012, 18:572-579 
14. Apte U, Thompson MD, Cui S, Liu B, Cieply B, Monga SP: Wnt/betacatenin signaling mediates oval cell response in rodents. Hepatology 2008, 47:288-295

15. Apte U, Singh S, Zeng G, Cieply B, Virji MA, Wu T, Monga SP: Betacatenin activation promotes liver regeneration after acetaminopheninduced injury. Am J Pathol 2009, 175:1056-1065

16. Monga SP: Role and regulation of beta-catenin signaling during physiological liver growth. Gene Expr 2014, 16:51-62

17. Wang S, Song K, Srivastava R, Dong C, Go GW, Li N, Iwakiri Y, Mani A: Nonalcoholic fatty liver disease induced by noncanonical Wnt and its rescue by Wnt3a. FASEB J 2015, 29:3436-3445

18. Okabe H, Yang J, Sylakowski K, Yovchev M, Miyagawa Y, Nagarajan S, Chikina M, Thompson M, Oertel M, Baba H, Monga SP, NejakBowen $\mathrm{KN}$ : Wnt signaling regulates hepatobiliary repair following cholestatic liver injury in mice. Hepatology 2016, 64:1652-1666

19. Zhang R, Kikuchi AT, Nakao T, Russell JO, Preziosi ME, Poddar M, Singh S, Bell AW, England SG, Monga SP: Elimination of Wnt secretion from stellate cells is dispensable for zonation and development of liver fibrosis following hepatobiliary injury. Gene Expr 2018. doi:10.3727/105221618X15373858350141, [Epub ahead of print]

20. Carpenter AC, Rao S, Wells JM, Campbell K, Lang RA: Generation of mice with a conditional null allele for Wntless. Genesis 2010, 48: $554-558$

21. Committee for the Update of the Guide for the Care and Use of Laboratory Animals; National Research Council: Guide for the Care and Use of Laboratory Animals: Eighth Edition. Washington, DC, National Academies Press, 2011

22. Okabe H, Delgado E, Lee JM, Yang J, Kinoshita H, Hayashi H, Tsung A, Behari J, Beppu T, Baba H, Monga SP: Role of leukocyte cell-derived chemotaxin 2 as a biomarker in hepatocellular carcinoma. PLoS One 2014, 9:e98817

23. Glass CK, Saijo K: Nuclear receptor transrepression pathways that regulate inflammation in macrophages and T cells. Nat Rev Immunol 2010, 10:365-376

24. Chawla A, Nguyen KD, Goh YP: Macrophage-mediated inflammation in metabolic disease. Nat Rev Immunol 2011, 11:738-749

25. Saha S, Bhanja P, Kabarriti R, Liu L, Alfieri AA, Guha C: Bone marrow stromal cell transplantation mitigates radiation-induced gastrointestinal syndrome in mice. PLoS One 2011, 6:e24072

26. Stefater JA 3rd, Ren S, Lang RA, Duffield JS: Metchnikoff's policemen: macrophages in development, homeostasis and regeneration. Trends Mol Med 2011, 17:743-752

27. Wynn TA, Chawla A, Pollard JW: Macrophage biology in development, homeostasis and disease. Nature 2013, 496:445-455

28. Lin SL, Li B, Rao S, Yeo EJ, Hudson TE, Nowlin BT, Pei H, Chen L, Zheng JJ, Carroll TJ, Pollard JW, McMahon AP, Lang RA, Duffield JS: Macrophage Wnt7b is critical for kidney repair and regeneration. Proc Natl Acad Sci U S A 2010, 107:4194-4199

29. Clouston AD, Jonsson JR, Powell EE: Hepatic progenitor cellmediated regeneration and fibrosis: chicken or egg? Hepatology 2009, 49:1424-1426

30. Wynn TA, Barron L: Macrophages: master regulators of inflammation and fibrosis. Semin Liver Dis 2010, 30:245-257
31. Ramachandran P, Pellicoro A, Vernon MA, Boulter L, Aucott RL, Ali A, Hartland SN, Snowdon VK, Cappon A, Gordon-Walker TT, Williams MJ, Dunbar DR, Manning JR, van Rooijen N, Fallowfield JA, Forbes SJ, Iredale JP: Differential Ly-6C expression identifies the recruited macrophage phenotype, which orchestrates the regression of murine liver fibrosis. Proc Natl Acad Sci U S A 2012, 109:E3186-E3195

32. Dal-Secco D, Wang J, Zeng Z, Kolaczkowska E, Wong $\mathrm{CH}$, Petri B, Ransohoff RM, Charo IF, Jenne CN, Kubes P: A dynamic spectrum of monocytes arising from the in situ reprogramming of CCR2+ monocytes at a site of sterile injury. J Exp Med 2015, 212: $447-456$

33. Karlmark KR, Zimmermann HW, Roderburg C, Gassler N, Wasmuth HE, Luedde T, Trautwein C, Tacke F: The fractalkine receptor CX(3)CR1 protects against liver fibrosis by controlling differentiation and survival of infiltrating hepatic monocytes. Hepatology 2010, 52:1769-1782

34. Michalopoulos GK, Barua L, Bowen WC: Transdifferentiation of rat hepatocytes into biliary cells after bile duct ligation and toxic biliary injury. Hepatology 2005, 41:535-544

35. Huch M, Dorrell C, Boj SF, van Es JH, Li VS, van de Wetering M, Sato T, Hamer K, Sasaki N, Finegold MJ, Haft A, Vries RG, Grompe M, Clevers H: In vitro expansion of single Lgr5+ liver stem cells induced by Wnt-driven regeneration. Nature 2013, 494: $247-250$

36. Henderson WR Jr, Chi EY, Ye X, Nguyen C, Tien YT, Zhou B, Borok Z, Knight DA, Kahn M: Inhibition of Wnt/beta-catenin/CREB binding protein (CBP) signaling reverses pulmonary fibrosis. Proc Natl Acad Sci U S A 2010, 107:14309-14314

37. Akhmetshina A, Palumbo K, Dees C, Bergmann C, Venalis P, Zerr P, Horn A, Kireva T, Beyer C, Zwerina J, Schneider H, Sadowski A, Riener MO, MacDougald OA, Distler O, Schett G, Distler JH: Activation of canonical Wnt signalling is required for TGF-beta-mediated fibrosis. Nat Commun 2012, 3:735

38. Viebahn CS, Benseler V, Holz LE, Elsegood CL, Vo M, Bertolino P, Ganss R, Yeoh GC: Invading macrophages play a major role in the liver progenitor cell response to chronic liver injury. J Hepatol 2010, 53:500-507

39. Banziger C, Soldini D, Schutt C, Zipperlen P, Hausmann G, Basler K, Wntless: a conserved membrane protein dedicated to the secretion of Wnt proteins from signaling cells. Cell 2006, 125:509-522

40. Wu J, Choi TY, Shin D: tomm22 Knockdown-mediated hepatocyte damages elicit both the formation of hybrid hepatocytes and biliary conversion to hepatocytes in zebrafish larvae. Gene Expr 2017, 17: $237-249$

41. Zhang P, Cai Y, Soofi A, Dressler GR: Activation of Wnt11 by transforming growth factor-beta drives mesenchymal gene expression through non-canonical Wnt protein signaling in renal epithelial cells. J Biol Chem 2012, 287:21290-21302

42. Liu X, Wu S, Xia Y, Li XE, Xia Y, Zhou ZD, Sun J: Wingless homolog Wnt11 suppresses bacterial invasion and inflammation in intestinal epithelial cells. Am J Physiol Gastrointest Liver Physiol 2011, 301:G992-G1003 